\title{
Fostering Sustainable Nutrition Behavior through Gamification
}

\author{
Verena Berger ${ }^{1, *}$ and Ulf Schrader ${ }^{2}$ \\ Received: 21 September 2015; Accepted: 7 January 2016; Published: 12 January 2016 \\ Academic Editors: Manfred Max Bergman and Marc A. Rosen \\ 1 Institute of Marketing Management, School of Management and Law, \\ Zurich University of Applied Sciences (ZHAW), Stadthausstrasse 14, Winterthur CH-8400, Switzerland \\ 2 Chair of Economic Education and Sustainable Consumption, Technische Universität Berlin, \\ Secretariat MAR 1-1, Marchstrasse 23, Berlin D-10587, Germany; schrader@tu-berlin.de \\ * Correspondence: verena.berger@zhaw.ch; Tel.: +41-58-934-6866
}

\begin{abstract}
The food choices consumers make have considerable consequences for the environment. In the Western world, about one-third of all negative environmental impact is directly related to food consumption. Although many consumers are concerned about environmental issues, this frequently has little effect on actual nutritional behavior and new approaches are needed to convert good intentions into action. Gamification could be a possible way to encourage both self-efficacy on the part of the consumer as well as normalizing such behavior socially. In this paper, central elements of the behavioral change model HAPA (health action process approach) are introduced to a gamification concept. The underlying frameworks of both concepts are then analyzed in order to develop propositions for use in the design of an effective gamification setting to promote sustainable nutritional behavior (SNB).
\end{abstract}

Keywords: sustainable nutrition; behavioural change; social norms; self-efficacy; gamification

\section{Introduction}

The field of nutrition is facing numerous social, ecological, and economic challenges. With the rising world population, more affluent nutritional habits, and changing lifestyles, the demand for food is expected to increase further [1], making nutrition and security of food supply major issues that will continue to concern us. Without fundamental changes in attitude and behavior, the current trends in global nutritional behavior may have dramatic consequences for our planet, including an increase in greenhouse gas emissions, the depletion of natural resources, and a reduction in biodiversity [2]. In addition, these trends are detrimental to both individual and public health as an increasing number of people suffer from obesity and other nutrition-related illnesses, causing health care costs to soar [3]. Modern eating habits are far from sustainable, accounting for about one-third of the total environmental impact in the Western world [4]. Hence, there is an urgent need for action which promotes behavioral change and encourages us to eat in a more responsible way.

Sustainable nutrition behavior (SNB) can have different meanings depending on what dimensions and criteria it encompasses. For the purposes of this paper, it refers to a set of criteria related to environmental impact, including low meat consumption, as well as the consumption of seasonal and organically grown foods [5]. The social, economic, and health dimensions of sustainable nutrition are therefore neglected here, despite the fact that meeting these criteria is in line with common dietary recommendations and an important factor in sustainable development [6].

Effective approaches to sensitize consumers and initiate change with regard to SNB are still scarce [7], not least because nutritional behavior is a complex issue influenced by many factors 
ranging from the biological and psychological to lifestyle issues [8-13]. Consequently, the majority of consumers struggle to make environmentally friendly food choices [14], and while they may be ecologically conscious in theory, their lifestyle is not. One reason for this is their inability to examine food products for environmental impact [15] due to insufficient product information or possibly an inability to interpret product labels meaningfully [16,17]. According to Tobler et al. [18], people who are more knowledgeable about climate change tend to exercise greater concern and feel more in control than others. However, knowledge alone is not enough: Humans are creatures of habit and habitual behavioral patterns prevent them from adopting a more climate-friendly lifestyle [19]. As habitual behavior is dependent on personal surroundings and, to a lesser extent, under greater intentional control than non-habitual behavior, traditional knowledge-oriented, educational approaches to change habits are not considered to be very effective [20-22].

One alternative approach already studied in the context of nutrition and health-related behavior is the use of social mechanisms to influence self-efficacy and social norms and thus improve self-regulation skills. Although the underlying processes of social norms are still not fully understood, various studies indicate that individuals use information about how others behave as a guide to appropriate behavior in a given context, especially in new, ambiguous, or uncertain situations [23]. There is also evidence that specific messages based on group behavior could have the power to influence health-related intentions by influencing perceived social norms and self-efficacy [24]. Incorporating the power of social mechanisms might therefore be a promising way to foster SNB in overcoming at least some environmental and health-related challenges.

Gamification is a concept that makes use of social mechanisms such as social influence or interaction by applying game mechanics [25]. Little is known as of yet about its effects on behavioral change, especially in the context of sustainable nutrition. However, this paper aims to provide theoretically substantiated recommendations on how to design an effective gamification approach to support SNB, especially for non-acting participants in the motivational phase, bringing together theory of health behavior change, self-efficacy, social norms, and gamification research. After setting the context and describing the relevant theoretical components, a conceptual model is presented and proposals are made for designing a gamification setting which may foster change towards greater SNB. This is then followed by a conclusion with limitations taken into account.

\section{Importance of Self-Efficacy and Social Norms for Behavioral Change}

Sustainable eating behavior on the part of the consumer is not only linked to environmental issues, but also to health issues. This fact inspired the use of the health action process approach (HAPA) developed by Schwarzer [26] (see Figure 1), a prominent model often applied to explain changes in health-promoting behavior and a suitable conceptual basis in the context of SNB.

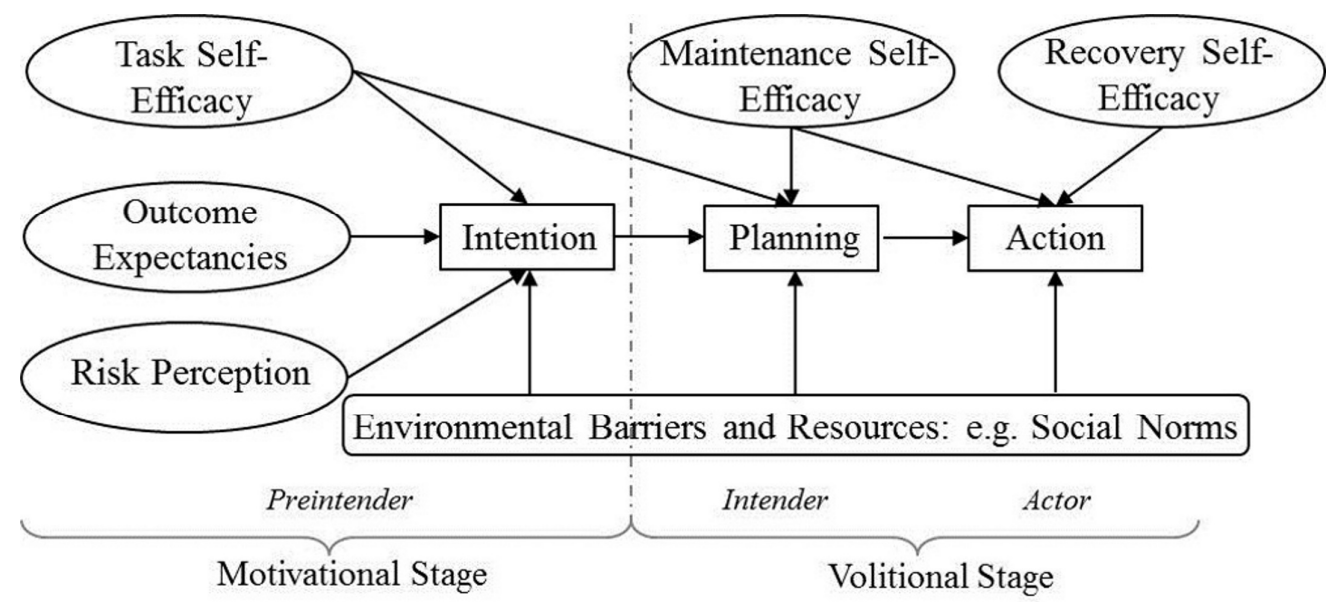

Figure 1. HAPA according to Schwarzer [26]. 
The HAPA provides a framework for explaining why people do or do not engage in a specific behavior, and overcomes limitations of other continuum and stage theories in attempting to explain behavioral change, such as the Theory of Reasoned Action (Fishbein and Ajzen [27]) or the Theory of Planned Behavior (Ajzen [28]). It also bridges the gap between intentions and behavior by considering planning as a construct which has been found to mediate the intention-behavior relation [26]. The model shares basic constructs with other behavior change models, such as self-efficacy, outcome expectancies, risk perception, goals, and plans [29], as well as barriers and resources impeding or fostering the change process. Although not explicitly referring to social norms, this well-established concept allows us to consider such drivers or constraints of behavior change.

According to Schwarzer, the relevance of the constructs considered depends on the stage within the behavioral change process. This process can be divided into two stages, namely the motivational and the volitional. The model suggests grouping individuals into "pre-intenders", "intenders", and "actors" by assessing their different psychological states. "Intenders", for example, are individuals who have reached the volitional stage. They are motivated to change but hesitate, lacking the right skills to turn intention into action. In the action phase, people have already adapted their mindset, are making plans, and are stable in their behavior. Utilizing these differences, behavior-specific stage algorithms can be employed to assess the stages [30] or when it comes to designing interventions. In designing an intervention for highly motivated individuals, for instance, only treatment components aimed at planning and action control have to be taken into account. In this context, self-efficacy (either as maintenance, task, or recovery self-efficacy) and social norms (which function as barriers or resources) are especially relevant.

\subsection{Self-Efficacy}

Self-efficacy is the extent or strength of belief in one's own capability to complete tasks successfully and achieve goals [31]. Individuals with high self-efficacy are more likely to complete difficult tasks and persist longer in those efforts than those who think that they cannot perform well.

The relevance of self-efficacy has been validated empirically in the motivational and action phase of behavioral change [32-34]. Research into the improvement of daily eating habits has found that intentions are translated into nutritional behavior by planning, and that self-efficacy moderates this mediation. If people lack self-efficacy "intentions are not well translated into nutrition behavior through planning" [35] (p. 260). This makes self-efficacy an important factor because only when people have a strong belief in their ability to behave effectively are they able to meet different challenges during the course of, for example, nutrition-related behavioral change. When designing an intervention for such individuals, treatment components aimed at strengthening self-efficacy should therefore be taken into account. In this connection, concepts closely related to self-efficacy are included in the self-determination theory (SDT) [36], which addresses both intrinsic and extrinsic motives for action [37,38]. The theory is based on three psychological needs: autonomy, competence and relatedness, which can be addressed by gamified interventions contributing to enjoyment, regardless of the specific content, complexity, or genre of games [39,40]. Game design elements such as feedback and rewards for tasks can foster the feeling of competence in the same way as self-efficacy. Within a gamified system, tasks of greater difficulty can be divided into smaller, less difficult tasks and, consequently, self-efficacy can be positively stimulated because larger accomplishments are recognized while smaller tasks accumulate [41]. This is especially important in motivating people with low initial self-efficacy. At the same time, people with high self-efficacy must also be kept at a task by experiencing satisfaction of the need for competence as well as having the autonomy to maintain or enhance intrinsic motivation.

\subsection{Social Norms}

Social norms are the accepted or implied rules about how people should and do behave [42,43]. These rules are generally accepted by a group and can guide the attitude, beliefs, and behavior of its 
members. This implies that the mere presence of others, or rather what is believed about their behavior, influences social behavior and can therefore affect performance. The power of social norms to predict eating behavior, among other things, has been demonstrated by various studies, e.g., [24,44,45].

Credible information about social norms can effectively influence behavior in the context of nutrition, which has been shown, for example, by Croker et al. [46] for fruit and vegetable consumption or by Lally et al. [47] for snacking behavior. This is because individuals observe the eating behavior of others and, considering it to be the norm, may use this information as a blueprint for their own behavior [48]. Whether this behavior is healthy or not depends on how the reference group's behavior is perceived: Misperceptions about the behavior of peers may lead to behavioral change towards this misperceived norm [49]. If a reference group is observed to prefer meat to vegetables, for example, this behavior is perceived as "normal", but with negative consequences in terms of sustainability.

In social norm research, there are two types of norms: descriptive norms which describe a specific behavior that prevails in a particular situation and is perceived as "normal", and injunctive norms which specify what ought to be done and imply penalization by the social group if behavior is deemed unacceptable [50]. Both types have implications for environmentally friendly behavior [48,51-53]. According to Cialdini [54], in following a norm-based approach, a combination of both types of norms would be most effective. However, disseminating social norm information may differ among groups and is thus context-dependent. Social norm intervention should therefore be tailored to a specific problem. For instance, the positive influence of descriptive norms, expressed by written information about other individuals' eating behavior, on intention and behavior was shown for vegetable consumption $[24,55,56]$, but no such effect was found for injunctive norms. However, it has been found that in situations where undesired behavior, such as using free plastic bags in a supermarket or buying much meat, is practiced by a majority, emphasis on a descriptive norm may result in "boomerang effects". Groot et al. [57] found that although the undesired behavior was shown, focusing on injunctive norm information prompted pro-environmental behavior. As descriptive norms are difficult to activate as desired pro-environmental behavior is often not yet shown, injunctive norm messages could be promising to encourage behavioral change.

Only one study [58] appears to have taken an initial step towards examining the effectiveness of injunctive norms in the context of food-related behavior. It depicted injunctive norms in the form of labels with simple emoticons and examined their effects on the perception of the taste and healthiness of snacks, but did not take into account the effects of emoticon labeling on objective measures of behavior such as actual purchasing and consumption.

When examining the impact of social norms, it is not only the framing of normative messages but also the effects of social influence by significant others such as family members or friends which have to be considered. Several studies exist which explore the impact of reference group proximity in different sustainability-related contexts, such as consumption of sustainable products [59], littering [50], or exercise and healthy diet behavior [60], but there is no study of norm messages incorporating reference group information in the context of sustainable nutrition.

\subsection{Influence of Reference Groups on Social Norm Effectiveness and Self-Efficacy}

When examining social norms within the context of nutrition, it may be necessary to consider that the effectiveness of social norms is tied to the relevance of reference groups [44]. Norms become effective only if a reference group is behaviorally relevant. Social identity theory suggests that norms linked to close reference groups may have a greater effect on intentions and behavior than those linked to more distant groups [61,62].

The more individuals identify with a norm reference group, the more likely they are to follow a norm associated with it. A strong sense of group identification also enhances perceptions of self-efficacy because individuals perceive their actions as representative of the collective [63]. The more similar or socially proximal that social group is, the greater the degree of similarity concerning dimensions such as age, gender, and attitudes, and the higher the degree of adoption of certain actions such as 
environmentally friendly behavior [64]. Yun and Silk [60] demonstrated that the effect of descriptive and injunctive norms on the intention (but not actual behavior) to eat a healthy diet differs depending on the reference group selected. Recent research by Stok et al. [24] confirms that majority-descriptive norms, for example the fact that most other referent group members eat sufficient vegetables, lead to a change in vegetable consumption, but only for people who strongly identify with the reference group. The above-mentioned results indicate the powerful interconnection between identity and behavior in the context of social norm interventions. Consequently, making relevant social identity salient, for instance by manipulating a descriptive norm, people are motivated to conform to the group's behavioral standards. Staunton et al. [65], who investigated the effects of negative descriptive norms (e.g., "Other students do not eat healthily") and positive injunctive norms (e.g., "Other students approve of eating healthily") on healthy eating, suggest that exposing individuals to a prominently negative descriptive norm is harmful when trying to create positive behavioral change since individuals look to referent others when making decisions about their own behavior.

Following on from this, social norm information could be effective in changing behavior towards sustainable nutrition. Nevertheless, for most people it will still not be easy to make this change. As stated by Bandura, an individual's self-efficacy plays a major role in how goals, tasks, and challenges are approached. It is therefore important to bear in mind that self-efficacy beliefs are formed by interpreting information primarily from four sources: mastery experience, social modeling, social persuasion, and psychological factors [31]. This means, for example, that successful experiences can lead to greater feelings of self-efficacy. Witnessing other people successfully completing a task is another source of self-efficacy. Seeing others succeed through sustained effort may raise an individual's belief in he or she being able to perform the task as well. Additionally, receiving verbal encouragement from others could persuade individuals to believe that they have the skills and capabilities to succeed. Notwithstanding, one's own responses and emotional reactions to situations also play an important role in self-efficacy. According to Bandura, this means that if stress can be minimized or mood improved during a challenging task, the sense of self-efficacy experienced by an individual can also increase.

Building on these sources, providing social norm information that shows proximal others engaging in a specific act such as sustainable nutrition enables one's own behavior to change accordingly. This is especially true for individuals who tend to compare themselves with others whenever they are uncertain about their own capabilities [66]. It may thus be assumed that people with low self-efficacy in particular would benefit from receiving information about behavioral changes accomplished within close reference groups. Therefore, it seems a practical step to exploit the findings from social norm research in the creation of a context-specific, methodically-constructed gamification design to foster a change in nutritional behavior.

\section{Gamification for Behavioral Change?}

Before relating the presented insights regarding self-efficacy and social norms to gamification, this chapter provides a short outline of the gamification concept.

Today, gamification is applied in healthcare, human resources, education, or corporate management to promote sport and other physical activity, motivate employees, create competition between teams, or encourage customer loyalty. It has become a common and useful feature of many smartphone applications, computer programs, and services as it combines information, action, and attraction by means of different game design elements, e.g., $[67,68]$. Without doubt, gamification provides not only positive emotional feelings such as hope or pride [69], but also frustration [70]. However, by using customized, e.g., avatars, an increasing sense of immersion and a feeling of affection for the character with which the individual identifies can be created [68], which in turn can have positive effects on learning [71]. Consequently, gamification may be a way to meet the need for effective, behavior-specific intervention by turning an intention to eat more sustainably into action. This can be achieved by adapting these elements in a context-specific and target group-specific manner. 
In this age of new media and constant information overload, interventions need to do more than simply provide information to be successful.

Gamification means the use of game design elements in non-game contexts [72], such as products, services, and information systems. According to Sailer et al. [73], the most common game design elements applied within a gamification environment are:

- Points: Rewards accumulated for certain actions

- Badges: Visual representations of achievements, which can be collected

- Leaderboards: Lists of all players, usually ranked by their success (e.g., based on points or badges awarded)

- Progress bars: Information about a player's current status towards achieving a goal

- Performance graphs: Information about a player's performance compared to previous performances

- Avatars: Visual representations of players

Gamification design means using these mechanisms in order to influence motivation productivity and the behavior of users positively. Empirical research and studies into gamification from a psychological perspective as well as its effects on behavioral change are scarce. Nevertheless, an attempt to link gamification theoretically to at least six principal perspectives of motivation research has been made by Sailer et al. [73]. From a HAPA perspective, motivation can be seen as a process that leads to the forming of behavioral intention followed by volition. In the motivational phase, people need to become motivated to change their behavior when addressing factors such as social influence perceptions including norms and modeling, and self-efficacy expectations. In general, when considering the continuum of motivation from SDT, "intenders" may be on different motivational levels. Many researchers claim that gamification can reduce the internal motivation that a user has for an activity since it replaces internal motivation with external motivation [74]. Others point out that extrinsic motivation rewards, achieved through competitive goals, can be an effective tool while intrinsic motivation is still evolving [75]. If gamification design can be made meaningful to the user through information, then intrinsic motivation can be improved as there is less need to emphasize external reward.

Nevertheless, when focusing on "intenders" the integration of external motivation by means of immediate feedback, in the form of points awarded for successful actions and the visualization of progress using a progress bar, may help activate behavior or compensate for the lack of intrinsic motivation towards sustainable nutritional behavior. A leaderboard function would enable individuals to compare themselves with other behaviorally relevant members of a reference group (e.g., their immediate peers), allowing them to assess their own strengths and fostering a spirit of competition. For "intenders" at the top of a leaderboard, a feeling of achievement may arise together with feelings of social relatedness due to shared goals and experiences and thus to a greater feeling of self-efficacy as well as intrinsic motivation [76]. Simultaneously, the leaderboard symbolizes the descriptive social norm by providing information on the "normal" behavior of relevant others. This might be particularly valuable for insecure people, unsure of whether they will be able to change (e.g., on account of low self-efficacy), since they could be motivated to continue because conforming to the perceived social norm and getting feedback would allow them to measure how close they already are to the accepted standard. If they happened to be close to the other people involved (proximal reference group), this would be even more effective. Because "intenders" are motivated to make changes but are held back by issues of self-confidence, this lack of self-efficacy could thus be remedied. If correctly designed and applied, gamification could initiate a process through which behavioral change may be fostered. It may function as an intervention affecting social norms and self-efficacy by presenting information about reference group norms in relation to the behavior of oneself and significant others. Consequently, gamification may affect the most crucial factors of the HAPA model, as depicted in Figure 2. 


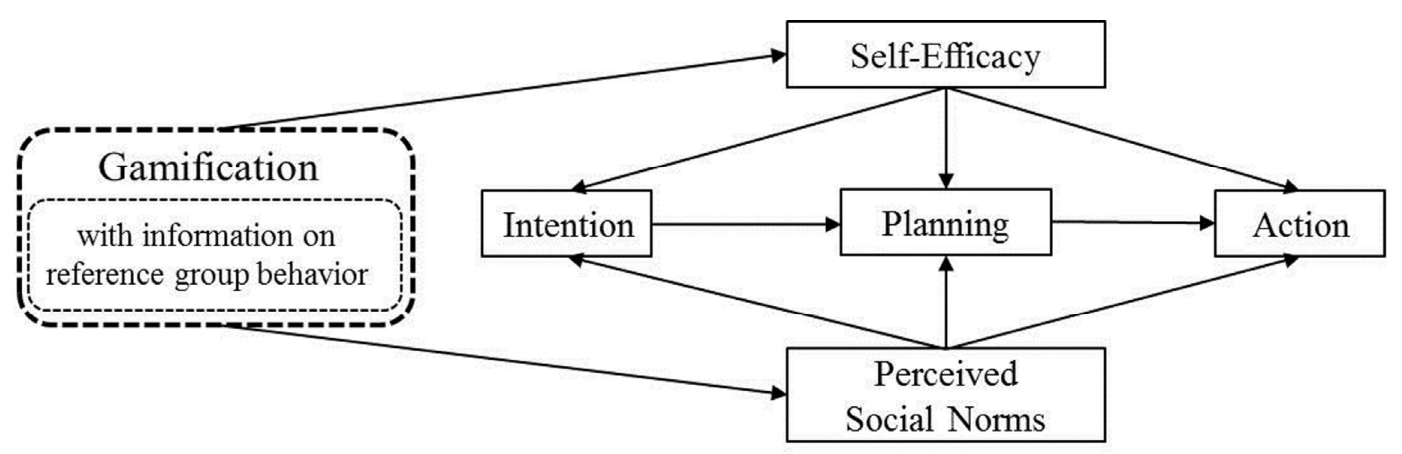

Figure 2. Using gamification to support behavior change.

\section{Designing Gamification to Promote Sustainable Nutritional Behavior}

Several propositions can be derived from considering gamification and its potential to transform "intenders" in particular into "actors" by activating social norms and increasing self-efficacy. In the following section, three propositions are presented on how gamification needs to be designed to promote SNB for "intenders". To illustrate how the gamification approach can be implemented in a real-life setting, an area of application is defined, in this case the workplace canteen or staff restaurant. As eating outside the home is an increasing trend [77,78], likely to continue in the future owing to changing lifestyles and time pressures, canteen meals form an important part of daily nutrition. For this reason, the environment offers a promising place for field-testing the propositions as it finds a large part of the target group ("intenders") in a real-life situation.

In methodological terms, the proposed gamification designs would have to be verified by conducting a field test both in and out of the domestic environment. Gamified online and offline approaches are possible depending on infrastructure and financial resources available. Gamification design effectiveness can be measured by applying the Menu Sustainability Index (MNI), an instrument that assesses the ecological and health impact of set meals [79], at the pilot company. It can also be used for pre-post measurement by providing information on the composition of chosen meals. The HAPA would act as a theoretical framework for data collection of the constructs relevant for measuring the effectiveness of stage-specific gamified approaches.

Proposition 1: The gamification design should show the diffusion of sustainable nutritional behavior within the reference group to activate perceived social norms.

As shown above, information about the eating behavior, customs, and accepted practices of others influences which foods individuals habitually buy and eat. When new patterns of behavior have to be adopted, visualizing the sustainable behavior of others by means of gamification may mark a path through the huge range of food on offer, potentially paving the way towards better long-term habits.

In demonstrating SNB through the behavior of relevant others, there needs to be at least one "sustainable" menu labeled accordingly using the MNI, with the first requirement being to offer transparency and orientation in a real-life canteen setting, as well as being the general basis for the application of game design elements.

Secondly, in conditions of persisting uncertainty, norms may exert great influence. It is therefore important that $\mathrm{SNB}$, which in this paper means choosing sustainable meals, is made visible so as to activate the desired norm. For instance, by introducing a points system, individual achievements when making a sustainable food choice can be rewarded by points representing individual SNB. The scores can be displayed in a leaderboard and ranked against other groups such as the company workforce as a whole, department members, or close team colleagues. Such a ranking or a bar displaying the average score is often used in gamified fitness applications such as Nike+ to promote physical activity, thereby allowing people to compare their ranking against others. It must be kept in mind that behavioral effects may only be evident if the majority of individuals display and maintain appropriate behavior. To reach "intenders" who are not yet behaving in a sustainable manner, it is important to reward 
simple and feasible food choices, thereby making goals attainable [80]. This means that they do not have to change their way of life completely and even small actions such as substituting an apple for a slice of cake should be proportionately rewarded.

Proposition 2: The gamification design should show that members of the relevant reference group are able to manage the change towards more sustainable nutritional behavior to increase the self-efficacy for that change.

As Bandura [31] points out, vicarious experiences provided by social models are one of the main sources that influence an individual's perceived self-efficacy. This means activating and increasing self-efficacy by seeing other similar people succeeding at a task would raise beliefs of being capable of mastering activities, including SNB. Following on from this, it might be very helpful for "intenders" to see that other relevant people have already followed SNB and to realize that it is possible to overcome the initial hurdles.

For concrete implementation, visual representations of "players" that embody relevant others such as work colleagues or role models can be created. The definition of the most appropriate individuals depends on the context and needs careful evaluation (see Proposition 3). Successful activities and achievements in relation to nutritional behavioral changes can be presented, for example, in the form of physical notices and on company intranet sites, reinforcing their visual and communicative impact. For "intenders", this implies that SNB can also be achieved by similar other "normal" or exemplary people. As vicarious experiences involve social comparisons with others and peer modeling, it may, however, be important to find the "correct" models first. Moreover, experiencing a feeling of mastery as well as realizing that you can be successful, albeit in small stages, and receiving encouragement may also improve self-efficacy. If the individual is unsuccessful, receiving feedback about how to change is important [31]. Feedback in terms of gamification on individual progress and success (e.g., in choosing the sustainable menu) could be used to encourage individuals. It could be implemented by receiving reward points or other elements to provide immediate feedback on performance [81] as well as by providing personalized information by means of additional text messages sent to the participating workforce that contain special praise implying that success is based on personal commitment. Nevertheless, from meta-analyses it is known that feedback does not always have a positive effect on performance [82] or the desired effect on self-efficacy [83]. According to van de Ridder et al. [84] this is because of the different ways in which feedback can be provided, including the various possibilities of framing (positive-negative), level of detail, or the timing of feedback (instantly or in an accumulated (offline) form) [85]. Although de Ridder et al. [84] have also demonstrated positive effects on performance and self-efficacy, self-efficacy itself seems to have a moderating effect and therefore influences the acceptance of feedback as well [86]. Despite these studies, effects of feedback on an "intender's" ability to activate and/or maintain SNB are not yet clear [87]. However, whether or not individuals with low self-efficacy continue the positive behavior may strongly depend on how the feedback is designed (leaderboard, positive or negative framing) and how it is combined with other measures and if it is in line with a person's self-conception; otherwise, it will be not accepted as valid [88]. As "intenders" in particular benefit from personal plans, a strategic planning type of message appears to be effective in combination with game design elements [89]. Providing feedback in terms of rewards can then relate individual performances to these specific, planned goals, which could improve self-efficacy.

Proposition 3: The gamification design should work with participants who are close to each other and form a relevant reference group in order to have a strong effect on social norm activation, self-efficacy, and more sustainable nutritional behavior.

As indicated earlier, the influencing effect of reference groups on social norms as well as on self-efficacy levels depends on choosing the "correct" model. Adopting the behavior of another person depends on the degree of similarity between the model and the relevant target audience. This means, for example, in order to attract younger people to SNB, it would make sense to use not only models of the same age but also individuals with a high socio-economic status or other opinion-formers. If one 
wanted to reach all "intenders" among the workforce, it follows that it would be sensible to employ models displaying a variety of socio-demographic characteristics.

Putting this into practice by means of gamification would require the implementation of a leaderboard or different leaderboard editions tailored to specific target groups, indicating, at least implicitly, SNB by people relevant to the target audience. This also implies that choosing one's own relevant reference group when comparing achievements should be possible. Research on group selection in the educational context shows that group performance and satisfaction can be enhanced when pairs of friends and, therefore, close group members are assigned to each other rather than to complete strangers [90]. In conjunction with this proposition, it would be necessary to find ways of categorizing program participants according to socio-demographic characteristics or other preferences to allow group formation. The potential of suitable grouping and social networking is known in co-operative online education [91], as well as in MMORPGs (Massively Multi-Player Online Role-Playing Games) that "are designed to provide a social environment where gamers can interact, form groups and complete tasks together." [92] (p. 42).

As already happens for the purposes of healthcare compliance [93], meaningful groups can be formed by using intelligent algorithms. With such an algorithm in place, it is more likely that the "intender" behaves in compliance with this group, adopting its eating norms and engaging in SNB through strong group identification because participants can be addressed by others who are close to them and identify with the target persons' characteristics. In the case of individuals with low self-efficacy during the motivational stage, the influence of relevant others could have a positive effect on self-efficacy towards the target behavior, which is rooted in Bandura's second source of self-efficacy: information coming from vicarious experience. This is simultaneously an opportunity and a challenge. If an individual is high on the self-efficacy scale, it may be that he or she is resisting the pressure of external influences so, by forming specific groups according to self-referential cognition, it may be possible to avoid or at least diminish these negative effects.

A group-specific leaderboard, for example, may show that close referent others have already started following sustainable nutritional behavior patterns and therefore illustrates the appropriate and predominant social norm at the same time. Any underlying reward structure must also consider the appropriate level of reward based on clear goals for the "intender" which are not perceived as a response to pressure or an attempt at external control [94].

\section{Conclusions}

New effective approaches that promote behavioral change and encourage better nutritional behavior are needed to avoid dramatic consequences for this planet as well as for personal and public health. Referring specifically to the behavioral change process, fostering habitual behavior patterns in areas such as nutrition is a challenging task.

As demonstrated by various studies on behavior change, self-efficacy and social norms play a major role at every stage of the behavioral change process, but its nature differs from phase to phase. Depending on the stage, different strategies are needed to move the individual successfully from deliberation to action. People who already have an intention but are not acting yet ("intenders") seem a promising target group in an initial step as they may need a smaller push to become an active person than a "pre-intender" would.

So why gamification in the fostering of sustainable nutritional behavior? There are good reasons from a practical as well as scientific point of view. Firstly, nutritional behavior, which is, to a large degree, habitualized and, in many cases, a relatively unreflective process, makes it a suitable candidate for gamification. According to the stated propositions, gamification can be designed to take into consideration reference group identification and social norm information, which may activate norms while increasing self-efficacy beliefs and therefore foster SNB in a specific practical setting. It could be a promising approach in helping to bridge the intention-behavior gap for a potentially large group of individuals who have made a decision to change their behavior patterns but have not yet taken 
any steps to put any of it into practice. Secondly, nutrition information alone is not enough to change food choices and dietary intake. Studies have shown that an even more important moderator than knowledge is personal motivation when changing eating habits, together with interventions that target self-efficacy [95-97]. Leading on to the third argument, gamification is not a game as such, but a design process involving motivation. As game design elements can be introduced to situations that are often considered boring and are used to create a (learning) experience based on personal skills and a psychological frame of mind, it has the potential to trigger behavioral change.

From a scientific point of view, by developing this proposed gamified approach, both findings as well as limitations from intervention research [98-100] can be addressed. Firstly, it is theory-driven and considers important concepts such as self-efficacy, stage of change, and social influences that are found to be crucial for the effectiveness of intervention. Secondly, the gamification design can be implemented by using offline media as well as new media technologies and can therefore be tailored to a specific target group. Testing the propositions allow a closer look at effectiveness regarding stage-specific differences which are addressed, at least on a small scale, in this paper's focus on the "intender". Thirdly, this approach and the exemplary case of application enables assessments before and after implementation as well as an evaluation of effectiveness based on experimental research design so that treatment effects can be compared to a control group.

Although some meaningful findings are expected, the concept has several limitations. Firstly, when field-testing the propositions in a real-life canteen/staff restaurant setting, it will be necessary to evaluate the menus provided as well as to collect pre-post data. In addition, adequate infrastructure and workforce for the implementation of the MNI will be needed. Although predictions will be made on effective gamification design, SNB will only be assessed in a specific out-of-home situation; no information will be gained about how the gamification design will affect an individual's overall nutritional behavior and how gamification design might foster behavioral change among other groups such as children, or in the domestic environment.

Secondly, as the study is designed to identify and find gamified approaches to motivate "intenders" towards making changes in nutritional behavior, other HAPA target groups such as "pre-intenders" have been neglected. For this target group, measures other than gamified interventions would be required, focusing more on raising awareness and accountability through risk and resource communication. For example, "pre-intenders" could be informed about the advantages and disadvantages of their nutritional behavior patterns, which might be more effective.

Thirdly, the "the look and feel" of the gamified system, including the graphical user interfacecomprising aspects of design such as colors, shapes, and layout together with dynamic elements, such as buttons, boxes, and menus, are necessary to make behavioral change fun. However, these physiological factors have not been addressed, though they represent Bandura's fourth source of self-efficacy.

While there is strong evidence that gamification might be an effective approach, it is important to gain more empirically based insights as experimental testing in a real-life setting is missing from much of today's normative messaging intervention research [101]. Consequently, more research is required to test the proposed gamification measures. Effective ways need to be found to provide customized, target group-specific information about different levels of self-efficacy and the most motivating reference groups playing a key role in nutritional decisions, in order to avoid the aforementioned boomerang effects.

Further experimental studies are needed to address inevitable questions about the actual or presumed effects of gamified interventions as well as their long-term effectiveness on behavioral change in the context of sustainable nutrition, including their effectiveness in preventing relapses. These should also take into account privacy attitudes and whether the application of gamification design might also cause reactance in addition to positive affective reactions.

Acknowledgments: The authors thank two anonymous reviewers for their substantial feedback which has helped to improve an earlier version of the paper. 
Author Contributions: Verena Berger developed the first draft of the paper. Both authors improved the draft for submission. Verena Berger further developed the manuscript according to reviewer comments. Both authors read and approved the final manuscript.

Conflicts of Interest: The authors declare no conflict of interest.

\section{References}

1. The Government Office for Science. The Future of Food and Farming: Challenges and Choices for Global Sustainability; Government Office for Science: London, UK, 2011; pp. 2-6.

2. BCFN Barilla Center; World Watch Institute. Eating Planet 2012: Nutrition today: A challenge for Mankind and the Planet; Edizioni Ambiente: Milan, Italy, 2012.

3. Keats, S.; Wiggins, S. Future Diets: Implication for Agriculture and Food Prices. Available online: http:/ / www.thehealthwell.info/node/ 697970 (accessed on 18 September 2015).

4. European Environment Agency. Household Consumption and the Environment; Office for Official Publications of the European Communities: Luxembourg Gare, Luxembourg, 2006.

5. Jungbluth, N.; Tietje, O.; Scholz, R.W. Food purchases: Impacts from the consumers' point of view investigated with a modular LCA. Int. J. Life Cycle Assess. 2000, 5, 134-142. [CrossRef]

6. Tobler, C.; Visschers, V.H.; Siegrist, M. Eating green. Consumers' willingness to adopt ecological food consumption behaviors. Appetite 2011, 57, 674-682. [CrossRef] [PubMed]

7. Freibauer, A.; Mathijs, E.; Brunori, G.; Damianova, Z.; Faroult, E.; Gomis, J.G.; O’Brien, L.; Treyer, S. Sustainable Food Consumption and Production in a Resource-Constrained World. European Commission-Standing Committee on Agricultural Research (The 3rd SCAR) Foresight Exercise. Available online: http:/ / www.egfar.org/sites/default/files/files/Foresight\%20Briefs/Erik\%20Mathijs_Brief\%2001_ Sustainable_Final.pdf (accessed on 18 September 2015).

8. Mäkiniemi, J.-P.; Vainio, A. Barriers to climate-friendly food choices among young adults in Finland. Appetite 2014, 74, 12-19. [CrossRef] [PubMed]

9. Gaspar, R. Understanding the Reasons for Behavioral Failure: A Process View of Psychosocial Barriers and Constraints to Pro-Ecological Behavior. Sustainability 2013, 5, 2960-2975. [CrossRef]

10. Young, W.; Hwang, K.; McDonald, S.; Oates, C.J. Sustainable consumption: Green consumer behaviour when purchasing products. Sustain. Dev. 2010, 18, 20-31. [CrossRef]

11. Scheibehenne, B.; Miesler, L.; Todd, P.M. Fast and frugal food choices: Uncovering individual decision heuristics. Appetite 2007, 49, 578-589. [CrossRef] [PubMed]

12. Worsley, A. Nutrition knowledge and food consumption: Can nutrition knowledge change food behaviour? Asia Pac. J. Clin. Nutr. 2002, 11, 579-585. [CrossRef]

13. Asp, E.H. Factors affecting food decisions made by individual consumers. Food Policy 1999, 24, $287-294$. [CrossRef]

14. French, S.A.; Shimotsu, S.T.; Wall, M.; Gerlach, A.F. Capturing the spectrum of household food and beverage purchasing behavior: A review. J. Am. Diet. Assoc. 2008, 108, 2051-2058. [CrossRef] [PubMed]

15. Lea, E.; Worsley, A. Australian consumers' food-related environmental beliefs and behaviours. Appetite 2008, 50, 207-214. [CrossRef] [PubMed]

16. Grunert, K.G.; Hieke, S.; Wills, J. Sustainability labels on food products: Consumer motivation, understanding and use. Food Policy 2014, 44, 177-189. [CrossRef]

17. Thøgersen, J. How May Consumer Policy Empower Consumers for Sustainable Lifestyles? J. Consum. Policy 2005, 28, 143-177. [CrossRef]

18. Tobler, C.; Visschers, V.H.; Siegrist, M. Addressing climate change: Determinants of consumers' willingness to act and to support policy measures. J. Environ. Psychol. 2012, 32, 197-207. [CrossRef]

19. Van't Riet, J.; Sijtsema, S.J.; Dagevos, H.; de Bruijn, G.-J. The importance of habits in eating behaviour. An overview and recommendations for future research. Appetite 2011, 57, 585-596. [CrossRef] [PubMed]

20. Rothman, A.J.; Sheeran, P.; Wood, W. Reflective and automatic processes in the initiation and maintenance of dietary change. Ann. Behav. Med. 2009, 38, 4-17. [CrossRef] [PubMed]

21. Ferguson, E.; Bibby, P.A. Predicting future blood donor returns: Past behavior, intentions, and observer effects. Health Psychol. 2002, 21, 513-518. [CrossRef] [PubMed] 
22. Aarts, H.; Verplanken, B.; van Knippenberg, A. Habit and information use in travel mode choices. Acta Psychol. 1997, 96, 1-14. [CrossRef]

23. Griskevicius, V.; Goldstein, N.J.; Mortensen, C.R.; Cialdini, R.B.; Kenrick, D.T. Going along versus versus going alone: When fundamental motives facilitate strategic (non)conformity. J. Pers. Soc. Psychol. 2006, 91, 281-294. [CrossRef] [PubMed]

24. Stok, M.F.; Verkooijen, K.T.; de Ridder, D.T.D.; de Wit, J.B.F.; de Vet, E. How norms work: Self-identification, attitude, and self-efficacy mediate the relation between descriptive social norms and vegetable intake. Appl. Psychol. Health Well-Being 2014, 6, 230-250. [CrossRef] [PubMed]

25. Hamari, J.; Koivisto, J. Social motivations to use gamification: An empirical study of gamifying exercise. In Proceedings of the 21st European Conference on Information Systems, Urtrecht, The Netherlands, 5-8 June 2013.

26. Schwarzer, R. Modeling health behavior change: How to predict and modify the adoption and maintenance of health behaviors. Appl. Psychol. 2008, 57, 1-29. [CrossRef]

27. Fishbein, M.; Ajzen, I. Belief, Attitude, Intention, and Behavior: An Introduction to Theory and Research; Addison-Wesley Pub. Co.: Boston, MA, USA, 1975.

28. Ajzen, I. From intentions to actions: A theory of planned behavior. In Action Control; Kuhl, J., Beckmann, J., Eds.; Springer: Berlin, Germany; Heidelberg, Germany, 1985; pp. 11-39.

29. Abraham, C.; Sheeran, P. Understanding and changing health behaviour: From health beliefs to self-regulation. In Understanding and Changing Health Behaviour: From Health Beliefs to Self-Regulation; Abraham, C., Norman, P., Conner, M., Eds.; Harwood Academic: Amsterdam, The Netherlands, 2000; pp. 3-24.

30. Lippke, S.; Ziegelmann, J.P.; Schwarzer, R.; Velicer, W.F. Validity of Stage Assessment in the Adoption and Maintenance of Physical Activity and Fruit and Vegetable Consumption. Health Psychol. 2009, 28, 183-193. [CrossRef] [PubMed]

31. Bandura, A. Self-efficacy: Toward a unifying theory of behavioral change. Psychol. Rev. 1977, 84, 191-215. [CrossRef] [PubMed]

32. Wiedemann, A.U.; Lippke, S.; Reuter, T.; Schüz, B.; Ziegelmann, J.P.; Schwarzer, R. Prediction of stage transitions in fruit and vegetable intake. Health Educ. Res. 2009, 24, 596-607. [CrossRef] [PubMed]

33. Sheeran, P. Intention-Behavior Relations: A Conceptual and Empirical Review. In European Review of Social Psychology; Stroebe, W., Hewstone, M., Eds.; John Wiley \& Sons, Ltd.: Chichester, UK, 2001; pp. 1-36.

34. Bandura, A. Self-efficacy: The Exercise of Control; Freeman: New York, NY, USA, 1997.

35. Schwarzer, R.; Richert, J.; Kreausukon, P.; Remme, L.; Wiedemann, A.U.; Reuter, T. Translating intentions into nutrition behaviors via planning requires self-efficacy: Evidence from Thailand and Germany. Int. J. Psychol. 2010, 45, 260-268. [CrossRef] [PubMed]

36. Ryan, R.M.; Rigby, C.S.; Przybylski, A. The Motivational Pull of Video Games: A Self-Determination Theory Approach. Mot. Emot. 2006, 30, 344-360. [CrossRef]

37. Ryan, R.M.; Deci, E.L. Self-determination Theory and the Facilitation of Intrinsic Motivation, Social Development, and Well-Being. Am. Psychol. 2000, 55, 68-78. [CrossRef] [PubMed]

38. Deci, E.L.; Ryan, R.M. Intrinsic Motivation and Self-Determination in Human Behavior; Plenum: New York, NY, USA, 1985.

39. Przybylski, A.K.; Rigby, C.S.; Ryan, R.M. A motivational model of video game engagement. Rev. Gen. Psychol. 2010, 14, 154-166. [CrossRef]

40. Wang, C.K.J.; Khoo, A.; Liu, W.C.; Divaharan, S. Passion and intrinsic motivation in digital gaming. Cyberpsychol. Behav. 2008, 11, 39-45. [CrossRef] [PubMed]

41. Reeves, B.; Read, J.L. Total Engagement: Using Games and Virtual Worlds to Change the Way People Work and Businesses Compete; Harvard Business Press: Boston, MA, USA, 2009.

42. Sherif, M. The Psychology of Social Norms; Harper \& brothers: New York, NY, USA, 1936.

43. Turner, J.C. Social Influence; Open University Press: Milton Keynes, UK, 1991.

44. Higgs, S. Social norms and their influence on eating behaviours. Appetite 2015, 86, 38-44. [CrossRef] [PubMed]

45. Ball, K.; Jeffery, R.W.; Abbott, G.; McNaughton, S.A.; Crawford, D. Is healthy behavior contagious: Associations of social norms with physical activity and healthy eating. Int. J. Behav. Nutr. Phys. Act. 2010, 7. [CrossRef] [PubMed] 
46. Croker, H.; Whitaker, K.L.; Cooke, L.; Wardle, J. Do social norms affect intended food choice? Prev. Med. 2010, 49, 190-193. [CrossRef] [PubMed]

47. Lally, P.; Cooke, L.; McGowan, L.; Croker, H.; Bartle, N.; Wardle, J. Parents' misperceptions of social norms for pre-school children's snacking behaviour. Publ. Health Nutr. 2012, 15, 1678-1682. [CrossRef] [PubMed]

48. Robinson, E.; Thomas, J.; Aveyard, P.; Higgs, S. What Everyone Else Is Eating: A Systematic Review and Meta-Analysis of the Effect of Informational Eating Norms on Eating Behavior. J. Acad. Nutri. Diet. 2014, 114, 414-429. [CrossRef] [PubMed]

49. Berkowitz, A.D. Higher Education Center for Alcohol and Other Drug Abuse and Violence Prevention. The Social Norms Approach: Theory, Research and Annotated Bibliography; U.S. Department of Education: Washington, DC, USA, 2004.

50. Cialdini, R.B.; Reno, R.R.; Kallgreen, C.A. A focus theory of normative conduct: Recycling the concept of norms to reduce littering in public places. J. Pers. Soc. Psychol. 1990, 58, 1015-1026. [CrossRef]

51. Stok, F.M.; de Ridder, D.T.; de Vet, E.; de Wit, J.B. Don't tell me what I should do, but what others do: The influence of descriptive and injunctive peer norms on fruit consumption in adolescents. Br. J. Health Psychol. 2014, 19, 52-64. [CrossRef] [PubMed]

52. Nolan, J.M.; Schultz, P.W.; Cialdini, R.B.; Goldstein, N.J.; Griskevicius, V. Normative social influence is underdetected. Pers. Soc. Psychol. Bull. 2008, 34, 913-923. [CrossRef] [PubMed]

53. Thøgersen, J. Norms for environmentally responsible behaviour: An extended taxonomy. J. Environ. Psychol. 2006, 26, 247-261. [CrossRef]

54. Cialdini, R.B. Crafting normative messages to protect the environment. Curr. Dir. Psychol. Sci. 2003, 12, 105-109. [CrossRef]

55. Robinson, E.; Fleming, A.; Higgs, S. Prompting healthier eating: Testing the use of health and social norm based messages. Health Psychol. 2014, 33, 1057-1064. [CrossRef] [PubMed]

56. Stok, F.M.; de Ridder, D.T.; de Vet, E.; de Wit, J.B.F. Minority talks: The influence of descriptive social norms on fruit intake. Psychol. Health 2012, 27, 956-970. [CrossRef] [PubMed]

57. De Groot, J.; Abrahamse, W.; Jones, K. Persuasive normative messages: The influence of injunctive and personal norms on using free plastic bags. Sustainability 2013, 5, 1829-1844. [CrossRef]

58. Vasiljevic, M.; Pechey, R.; Marteau, T.M. Making food labels social: The impact of colour of nutritional labels and injunctive norms on perceptions and choice of snack foods. Appetite 2015, 91, 56-63. [CrossRef] [PubMed]

59. Salazar, H.A.; Oerlemans, L.; van Stroe-Biezen, S. Social influence on sustainable consumption: Evidence from a behavioural experiment. Int. J. Consum. Stud. 2013, 37, 172-180. [CrossRef]

60. Yun, D.; Silk, K.J. Social norms, self-identity, and attention to social comparison information in the context of exercise and healthy diet behavior. Health Commun. 2011, 26, 275-285. [CrossRef] [PubMed]

61. Terry, D.J.; Hogg, M.A. Group Norms and the Attitude-Behavior Relationship: A Role for Group Identification. Pers. Soc. Psychol. Bull. 1996, 22, 776-793. [CrossRef]

62. Tajfel, H.; Turner, J.C. An integrative theory of intergroup conflict. Soc. Psychol. Intergr. Relat. 1979, 33, 94-109.

63. De Cremer, D.; van Vugt, M. Collective identity and cooperation in a public goods dilemma: A matter of trust or self-efficacy? Curr. Res. Soc. Psychol. 1998, 3, 1-11.

64. Goldstein, N.J.; Cialdini, R.B.; Griskevicius, V. A Room with a viewpoint: Using social norms to motivate environmental conservation in hotels. J. Consum. Res. 2008, 35, 472-482. [CrossRef]

65. Staunton, M.; Louis, W.R.; Smith, J.R.; Terry, D.J.; McDonald, R.I. How negative descriptive norms for healthy eating undermine the effects of positive injunctive norms. J. Appl. Soc. Psychol. 2014, 44, 319-333. [CrossRef]

66. Gibbons, F.X.; Buunk, B.P. Individual differences in social comparison: Development of a scale of social comparison orientation. J. Pers. Soc. Psychol. 1999, 76, 129-142. [CrossRef] [PubMed]

67. Hendriks, M. Gaming the System: Making Personalised Learning Fun. Master's Thesis, Radboud University Nijmegen, Nijmegen, The Netherlands, 2015.

68. González-González, C.S.; Toledo-Delgado, P.; Padrón, M.; Santos, E.; Cairos, M. Including Gamification Techniques in the Design of TANGO: H Platform. J. Teknol. 2013, 63, 77-84. [CrossRef]

69. McGonigal, J. Reality Is Broken: Why Games Make Us Better and How They Can Change the World; Penguin Press: New York, NY, USA, 2011. 
70. Lazzaro, N. Why We Play Games: Four Keys to More Emotion Without Story. 2004. Available online: http://www.xeodesign.com/xeodesign_whyweplaygames.pdf (accessed on 8 December 2015).

71. Lee, J.; Hammer, J. Gamification in Education: What, How, Why Bother? Acad. Exch. Q. 2011, 15, 1-5.

72. Deterding, S.; Khaled, R.; Nacke, L.; Dixon, D. Gamification: Toward a definition. In Proceedings of the CHI 2011 Gamification Workshop, Vancouver, BC, Canada, 7-12 May 2011.

73. Sailer, M.; Hanse, J.; Mandl, H.; Klevers, M. Psychological perspectives on motivation through gamification. Interact. Des. Archit. 2013, 19, 18-37.

74. Nicholson, S. A User-Centered Theoretical Framework for Meaningful Gamification. In Proceedings of the Games+Learning+Society 8.0, Madison, WI, USA, 13-15 June 2012.

75. Rimm, S.B. Underachievement Syndrome: Causes and Cures; Apple: Watertown, WI, USA, 1986.

76. Westhead, P.; Wright, M. Entrepreneurship: A very Short Introduction; Oxford University Press: Oxford, UK, 2013.

77. Turrini, A.; Arganini, C.; D'Addezio, L. HECTOR Deliverable 6.2: Report on food services available in the European catering sector. In Eating out: Habits, Determinants, and Recommendations for Consumers and the European Catering Sector; Karger Publishers: Basel, Switzerland, 2009.

78. Lachat, C.; Nago, E.; Verstraeten, R.; Roberfroid, D.; van Camp, J.; Kolsteren, P. Eating out of home and its association with dietary intake: A systematic review of the evidence. Obes. Rev. 2012, 13, 329-346. [CrossRef] [PubMed]

79. Hauck, R.; Müller, C. Der Menü-Nachhaltigkeitsindex als Datenbankanwendung. Transfer 2013, 3, 8. Available online: https:/ /www.zhaw.ch/storage/lsfm/forschung/transfer/2013-3-ias.pdf (accessed on 11 December 2015).

80. Galbicka, G. Shaping in the 21st century: Moving percentile schedules into applied settings. J. Appl. Behav. Anal. 1994, 27, 739-760. [CrossRef] [PubMed]

81. Richter, G.; Raban, D.R.; Rafaeli, S. Studying Gamification: The Effect of Rewards and Incentives on Motivation. In Gamification in Education and Business; Springer International Publishing: New York, NY, USA, 2015; pp. 21-46.

82. Kluger, A.N.; DeNisi, A. The Effects of Feedback Interventions on Performance: A Historical Review, a Meta-Analysis, and a Preliminary Feedback Intervention Theory. Psychol. Bull. 1996, 119, 254-284. [CrossRef]

83. Prestwich, A.; Kellar, I.; Parker, R.; MacRae, S.; Learmonth, M.; Sykes, B.; Taylor, N.; Castle, H. How can self-efficacy be increased? Meta-analysis of dietary interventions. Health Psychol. Rev. 2014, 8, 270-285. [CrossRef] [PubMed]

84. Van de Ridder, J.M.M.; Peters, C.M.M.; Stokking, K.M.; de Ru, J.A.; ten Cate, O.T.J. Framing of feedback impacts student's satisfaction, self-efficacy and performance. Adv. Health Sci. Educ. Theory Pract. 2015, 20, 803-816. [CrossRef] [PubMed]

85. Weiser, P.; Bucher, D.; Cellina, F.; de Luca, V. A Taxonomy of Motivational Affordances for Meaningful Gamified and Persuasive Technologies. In Building the Knowledge Base for Environmental Action and Sustainability, Adjunct Proceedings of the 29th International Conference on Informatics for Environmental Protection and the 3rd International Conference on ICT for Sustainability, Copenhagen, Denmark, 7-9 September 2015; Kvist, J.V., Jensen, S., Wohlgemuth, V., Preist, C., Eriksson, E., Eds.; Department of Geosciences and Natural Resource Management, University of Copenhagen: Copenhagen, Denmark, 2015; pp. 271-280.

86. Nease, A.A.; Mudgett, B.O.; Quinones, M.A. Relationships Among Feedback Sign, Self-Efficacy, and Acceptance of Performance Feedback. J. Appl. Psychol. 1999, 84, 806-814. [CrossRef]

87. Baranowski, M.T.; Bower, P.K.; Krebs, P.; Lamoth, C.J.; Lyons, E.J. Effective Feedback Procedures in Games for Health. Games Health J. 2013, 2, 320-326. [CrossRef] [PubMed]

88. Swann, W.B.; Griffin, J.J.; Predmore, S.C.; Gaines, B. The cognitive-affective crossfire: When self-consistency confronts self-enhancement. J. Pers. Soc. Psychol. 1987, 52, 881-889. [PubMed]

89. Godinho, C.A.; Alvarez, M.-J.; Lima, M.L.; Schwarzer, R. Health messages to promote fruit and vegetable consumption at different stages: A match-mismatch design. Psychol. Health 2015, 30, 1410-1432. [CrossRef] [PubMed]

90. Mahenthiran, S.; Rouse, P.J. The impact of group selection on student performance and satisfaction. Int. J. Educ. Manag. 2000, 14, 255-265. [CrossRef] 
91. Dalsgaard, C.; Paulsen, M.F. Transparency in Cooperative Online Education. Int. Rev. Res. Open Distance Learn. 2009, 10, 239-287.

92. Hussain, Z.; Griffiths, M.D. A Qualitative Analysis of Online Gaming. Int. J. Cyber Behav. Psychol. Learn. 2014, 4, 41-57. [CrossRef]

93. Lin, R.J.; Ramakrishnan, S.; Chang, H.; Spraragen, S.; Zhu, X. Designing a web-based behavior motivation tool for healthcare compliance. Hum. Factors Ergon. Manuf. Serv. Ind. 2013, 23, 58-67. [CrossRef]

94. Mekler, E.D.; Brühlmann, F.; Opwis, K.; Tuch, A.N. Do Points, Levels and Leaderboards Harm Intrinsic Motivation? An Empirical Analysis of Common Gamification Elements. Assoc. Comput. Mach. 2013, 13, 66-73.

95. Hoefkens, C.; Pieniak, Z.; van Camp, J.; Verbeke, W. Explaining the effects of a point-of-purchase nutrition-information intervention in university canteens: A structural equation modelling analysis. Int. J. Behav. Nutr. Phys. Act. 2012, 9. [CrossRef] [PubMed]

96. Holdsworth, M.; Haslam, C. A review of point-of-choice nutrition labelling schemes in the workplace, public eating places and universities. J. Hum. Nutr. Diet. 1998, 11, 423-445. [CrossRef]

97. Contento, I.R.; Randell, J.S.; Basch, C.E. Review and Analysis of Evaluation Measures Used in Nutrition Education Intervention Research. J. Nutr. Educ. Behav. 2002, 34, 2-25. [CrossRef]

98. Steg, L.; Vlek, C. Encouraging pro-environmental behaviour: An integrative review and research agenda. J. Environ. Psychol. 2009, 29, 309-317. [CrossRef]

99. Noar, S.M.; Benac, C.N.; Harris, M.S. Does tailoring matter? Meta-analytic review of tailored print health behavior change interventions. Psychol. Bull. 2007, 133, 673-693. [CrossRef] [PubMed]

100. Grimshaw, J.M.; Shirran, L.; Thomas, R.; Mowatt, G.; Fraser, C.; Bero, L.; Grilli, R.; Harvey, E.; Oxman, A.; O’Brien, M.A. Changing Provider Behavior: An Overview of Systematic Reviews of Interventions. Med. Care 2001, 39, II2-II45. [CrossRef] [PubMed]

101. Bernedo, M.; Ferraro, P.J.; Price, M. The persistent impacts of norm-based messaging and their implications for water conservation. J. Consum. Policy 2014, 37, 437-452. [CrossRef]

(C) 2016 by the authors; licensee MDPI, Basel, Switzerland. This article is an open access article distributed under the terms and conditions of the Creative Commons by Attribution (CC-BY) license (http:/ / creativecommons.org/licenses/by/4.0/). 